\title{
8 \\ OPEN ACCESS \\ Utility of autonomic testing for the efficient diagnosis and effective pharmacological management of neurogenic orthostatic hypotension
}

\author{
Sami bin Alam, Waiel Almardini, Amer Suleman
}

The Heartbeat Clinic, McKinney, Texas, USA

Correspondence to Dr Sami bin Alam, sba0801@gmail.com

Accepted 25 July 2019

Check for updates

(c) BMJ Publishing Group Limited 2019. Re-use permitted under CC BY-NC. No commercial re-use. See rights and permissions. Published by BMJ.

To cite: Alam Sbin, Almardini W, Suleman A. BMJ Case Rep 2019:12:e228423. doi:10.1136/bcr-2018-

228423

\section{SUMMARY}

A 62-year-old man presented with a 2-year history of syncope, collapse and fluctuating blood pressure (BP). His medications included midodrine $(10 \mathrm{mg}$, three times per day) and fludrocortisone $(0.1 \mathrm{mg}$, two times per day), but neither treatment afforded symptomatic relief. Autonomic testing was performed. Head-up tilt table testing revealed a supine BP of $112 / 68 \mathrm{~mm} \mathrm{Hg}$ (heart rate, 74 beats per minute (bpm)) after 6 min, which dropped to $76 / 60 \mathrm{~mm} \mathrm{Hg}$ (83 bpm) within 2 min of $80^{\circ}$ head-up tilt. Findings from a heart rate with deep breathing test and a Valsalva test were consistent with autonomic dysfunction. The patient was diagnosed with neurogenic orthostatic hypotension and treated with droxidopa ( $100 \mathrm{mg}$, two times per day; titrated to $100 \mathrm{mg}$, one time per day). After initiating treatment with droxidopa, the patient no longer reported losing consciousness on standing and experienced improvement in activities of daily living. These improvements were maintained through 1 year of follow-up.

\section{BACKGROUND}

Syncope can have a variety of aetiologies and may result in falls and associated injuries. ${ }^{12}$

Syncope is defined as a sudden yet transient complete loss of consciousness in which the individual is unable to maintain postural tone, followed by rapid and spontaneous recovery. ${ }^{34}$

Standing for 2 to $3 \mathrm{~min}$ is usually sufficient to see the fall in blood pressure (BP) associated with syncope, however in the case presented here, BP was measured after $5 \mathrm{~min}$ of standing. ${ }^{4}$ Determining the underlying cause of syncopal episodes is an important diagnostic step to appropriately guide management (table 1). A relatively common cause of syncope is orthostatic hypotension $(\mathrm{OH})$, which is a drop in BP of $\geq 20 \mathrm{~mm} \mathrm{Hg}$ systolic or $\geq 10 \mathrm{~mm}$ $\mathrm{Hg}$ diastolic within a few minutes of standing. ${ }^{15}$

Neurogenic $\mathrm{OH}(\mathrm{nOH}$; that is, $\mathrm{OH}$ resulting from autonomic dysfunction) can be differentiated from non-neurogenic causes of $\mathrm{OH}$ (eg, hypovolaemia) clinically by autonomic function tests and by an insufficient compensatory heart rate (HR) increase on standing. ${ }^{67}$ Common clinical signs and symptoms of $\mathrm{nOH}$ include dizziness, lightheadedness, syncope and falls. ${ }^{8}$ Neurogenic $\mathrm{OH}$ is commonly comorbid with other disorders associated with autonomic dysfunction, including Parkinson's disease (PD), multiple system atrophy, pure autonomic failure, dementia with Lewy bodies and type 2 diabetes. ${ }^{69}$ Neurogenic $\mathrm{OH}$ increases the risk of falls, which in turn interferes with activities of daily living and increases the burden of symptoms for patients and their caregivers. ${ }^{1}{ }^{1011}$

In those cases in which the aetiology of a patient's syncope is unclear after initial evaluation and an ECG has ruled out a cardiac cause of syncope, referral for autonomic testing may aid in pinpointing the cause and guide decisions of the most appropriate steps in treating and managing the symptoms of the patient. ${ }^{2}{ }^{12}$ In this context, autonomic testing should include continuous BP monitoring during prolonged head-up tilt (HUT) on a tilt table, HR in response to paced breathing and $\mathrm{BP}$ in response to the Valsalva manoeuvre. ${ }^{2}{ }^{12}$ Decreased autonomic function, if observed, in this battery of tests indicates a neurogenic origin of $\mathrm{OH}$ and that the syncope is neurally mediated. Such a diagnosis should suggest a course of treatment. ${ }^{812}$

When the cause of syncope has been identified as $\mathrm{OH}$ or $\mathrm{nOH}$, pharmacological management of the condition may be necessary. ${ }^{8}$ Droxidopa, a norepinephrine prodrug, is the only drug currently approved by the US Food and Drug Administration to treat symptoms of $\mathrm{nOH}$ in adults, ${ }^{8} 13$ whereas midodrine, an alpha-1 adrenergic agonist, is approved to treat symptoms of $\mathrm{OH} .{ }^{14}$

\section{CASE PRESENTATION}

A 62-year-old man was evaluated for a 2-year history of syncope, collapse and fluctuating BP. His medical history included Hodgkin lymphoma, lupus, type 2 diabetes mellitus, autonomic neuropathy, hypercholesterolaemia, hypothyroidism and orthostatic hypotension. He was being treated with gabapentin $(300 \mathrm{mg}$, two times per day, saxagliptin (5 mg, one time per day (QD)), pravastatin $(40 \mathrm{mg}$ QD), levothyroxine sodium (100 mg QD), omeprazole $(20 \mathrm{mg}$ QD), prednisone $(10 \mathrm{mg}$, every other day), midodrine (10 mg, three times per day) and fludrocortisone ( $0.1 \mathrm{mg}$ two times per day).

At the time of his initial evaluation, the patient reported that his syncope was progressively worse over the past 3 months. Although his episodes of syncope were previously preceded by dizziness and nausea, they had begun to occur without warning. $\mathrm{He}$ also reported a 5-year history of orthostatic hypotension, with a supine BP of approximately $100 / 66 \mathrm{~mm} \mathrm{Hg}$ and a standing BP as low as 


\begin{tabular}{|c|c|c|c|c|}
\hline & \multicolumn{2}{|l|}{ Orthostatic hypotension } & \multicolumn{2}{|l|}{ Syncope } \\
\hline & Neurogenic & Non-neurogenic & Neurocardiogenic & Cardiac \\
\hline Causes & $\begin{array}{l}\text { Associated with autonomic failure } \\
\text { disorders }\end{array}$ & $\begin{array}{l}\text { Due to extrinsic factors (eg, } \\
\text { hypovolaemia, medication use) }\end{array}$ & $\begin{array}{l}\text { Associated with emotional stress } \\
\text { or pain }\end{array}$ & $\begin{array}{l}\text { Arrhythmia } \\
\text { Structural cardiac disease }\end{array}$ \\
\hline $\begin{array}{l}\text { Clinical } \\
\text { features }\end{array}$ & $\begin{array}{l}\text { BP drop of } \geq 20 \mathrm{~mm} \mathrm{Hg} \text { systolic or } \\
\geq 10 \mathrm{~mm} \mathrm{Hg} \text { diastolic on standing } \\
\text { Insufficient compensatory HR increase } \\
\text { on standing ( }<15 \mathrm{bpm})\end{array}$ & $\begin{array}{l}\text { BP drop of } \geq 20 \mathrm{~mm} \mathrm{Hg} \text { systolic or } \\
\geq 10 \mathrm{~mm} \mathrm{Hg} \text { diastolic on standing } \\
\text { Appropriate compensatory HR } \\
\text { increase on standing (>15 bpm) }\end{array}$ & $\begin{array}{l}\text { Vasodepressor reflex characterised } \\
\text { by a sudden drop in BP that may } \\
\text { occur after an increase in HR }\end{array}$ & $\begin{array}{l}\text { Low cardiac output due to structural } \\
\text { or electrical heart abnormalities } \\
\text { Occurs during exertion or when } \\
\text { supine }\end{array}$ \\
\hline
\end{tabular}

BP, blood pressure; bpm, beats per minute; HR, heart rate.

\begin{tabular}{ll}
\hline Table 2 & \multicolumn{1}{c}{ Signs of possible autonomic dysfunction ${ }^{21}$} \\
\hline Evaluation & Symptom \\
\hline Eyes & $\begin{array}{l}\text { Abnormal pupillary reflexes } \\
\text { Cardiovascular system }\end{array}$ \\
$\begin{array}{l}\text { Orthostatic hypotension } \\
\text { Supine hypertension }\end{array}$ \\
Gastrointestinal system & $\begin{array}{l}\text { Constipation } \\
\text { Dysphagia }\end{array}$ \\
Urinary tract & $\begin{array}{l}\text { Incontinence } \\
\text { Nocturia }\end{array}$ \\
Sexual dysfunction & Erectile dysfunction \\
\hline Sweat glands & Patchy sweating \\
\hline
\end{tabular}

50/40 mm Hg. His low standing BP and episodes of syncope persisted despite daily treatment with fludrocortisone and midodrine. Initial cardiac evaluation revealed a systolic murmur but was otherwise unremarkable. Other than $\mathrm{OH}$, a clinical manifestation of possible cardiovascular autonomic dysfunction, no other signs of autonomic dysfunction were noted during examination (table 2). Additionally, the patient showed no signs of hypovolaemia (ie, extremities were not cold, moist mucous membranes, no increase in urine specific gravity) or of amyloidosis (ie, lack of tongue swelling). Negative findings on serum protein electrophoresis and fat pad biopsy confirmed the lack of amyloidosis.

\section{INVESTIGATIONS}

Autonomic function testing was performed to determine whether the $\mathrm{OH}$ was neurogenic in origin. Tilt table testing revealed a BP drop from $112 / 68 \mathrm{~mm} \mathrm{Hg}(\mathrm{HR}, 74 \mathrm{bpm})$ after $6 \mathrm{~min}$ in the supine position to $76 / 60 \mathrm{~mm} \mathrm{Hg}(83 \mathrm{bpm})$ within $2 \mathrm{~min}$ of tilt to the $80^{\circ}$ head-up position; this BP drop was accompanied by dizziness and weakness at 2 min of tilt and presyncope at $4 \mathrm{~min}$ of tilt. Continuous recording with transcranial Doppler during tilt testing indicated no changes in mean cerebral blood flow. ECG tracings during the HR with deep breathing test (paced breathing at six breaths per minute) showed an expiration/inhalation ratio of 1.02, which is abnormal for the patient's age and sex, indicating depressed baseline autonomic tone and decreased vagal tone. Valsalva testing (measured at $40 \mathrm{~mm} \mathrm{Hg}$ ) revealed a Valsalva ratio of 1.15 , which is also abnormal for the patient's age and sex. Taken together, the results of autonomic testing were consistent with a diagnosis of idiopathic $\mathrm{nOH}$ for this patient.

\section{TREATMENT}

The patient was prescribed droxidopa $(100 \mathrm{mg}$ two times per day) to treat symptoms of $\mathrm{nOH}$. Treatment with droxidopa was reduced to $100 \mathrm{mg}$ QD because of nocturnal hypertension, for which he was prescribed a nitroglycerin patch as needed $(0.2 \mathrm{mg}$, transdermal). The patient continued to take both fludrocortisone and midodrine.

\section{OUTCOME AND FOLLOW-UP}

After initiating treatment with droxidopa, the patient reported he no longer lost consciousness on standing, although he still experienced some symptoms of presyncope, such as lightheadedness. One year after initiating droxidopa treatment, these improvements were maintained. The mitigation of his symptoms has improved his activities of daily living and decreased the burden of $\mathrm{nOH}$ on both the patient and his caregivers.

\section{DISCUSSION}

Determination of the underlying mechanism of syncope is critical for choosing an appropriate treatment and management

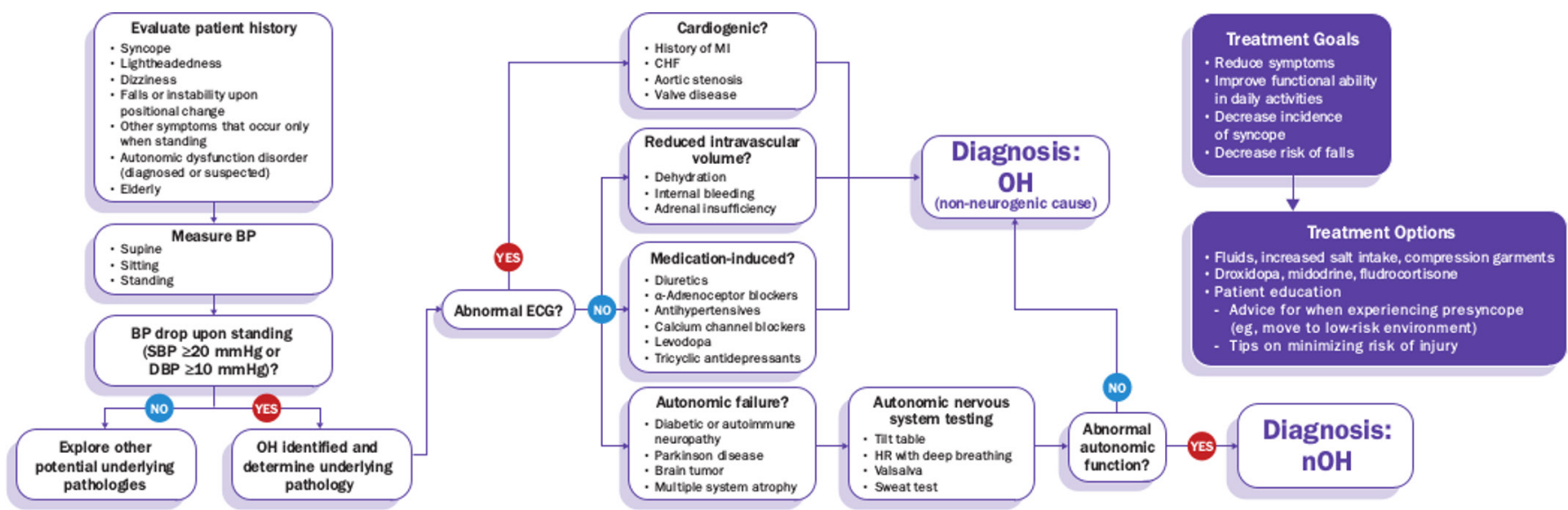

Figure 1 Diagnostic algorithm and treatment options for neurogenic orthostatic hypotension. BP, blood pressure; CHF, congestive heart failure; DBP, diastolic BP; HR, heart rate; MI, myocardial infarction; $\mathrm{nOH}$, neurogenic orthostatic hypotension; $\mathrm{OH}$, orthostatic hypotension; SBP, systolic BP. 
protocol. ${ }^{12}$ A proposed diagnostic algorithm should include a detailed patient history and physical examination (including supine and standing BP measurements and an ECG; figure 1). ${ }^{12}$ If determination of the mechanism of syncope is inconclusive after initial examinations, then autonomic function testing is warranted. ${ }^{2} 12$

The underlying causes of $\mathrm{nOH}$ can be varied, and there are multiple factors to be considered in the management of $\mathrm{nOH}$, especially in the face of comorbid conditions. A case report

Patient's perspective

My father's case had a slow process. I'm not sure how long he had this, because his symptoms began around the same time he was diagnosed with cancer in 2011. It continued to happen even after chemo. His blood pressure would get really low. He lost his brother in a motorcycle accident. We thought maybe the trauma or stress was causing his blood pressure to go crazy. Medications to control his blood pressure were not helping. He was taking three medications, and they were not even gapping the bridge. Another physician thought it could be postural orthostatic tachycardia syndrome, which is why my father was referred to The Heartbeat Clinic. They wanted to do tests to be sure about the diagnosis before any medication was prescribed. We couldn't even walk from the car to the office without my dad going down and passing out. He couldn't even use the restroom without passing out. He had broken ribs and busted his head open from passing out and falling. He passed out six to seven times per day. My mom would try to get him to a chair real quick. We needed to lift his legs to get his blood circulating, but my mother is small and couldn't get him off the floor. By the time he turned 60 , he was forced to retire because his health was so awful. His doctor provided albumin and intravenous fluids, which would last for about a week or 2 weeks. We were going to McKinney (The Heartbeat Clinic) a lot. That's when we finally got the diagnosis of neurogenic orthostatic hypotension. The first dose shot his BP up, so they brought it down to $100 \mathrm{mg}$. He doesn't have a normal life because his BP still gets low, but he no longer passes out several times per day.

If we could help somebody else by sharing this story, that would be wonderful. My father's quality of life taking no medication was just awful. Is it perfect? By no means not, but I believe he would not be here with us today without this treatment. He can at least function in his home. He needed to get used to using a wheelchair on outings. We do the (nitroglycerin) patches at night if his blood pressure is really high. My advice to patients and families is if you take it slowly you can figure out what works best for you. My father's quality of life has been so much better than when we started this journey.

My advice for doctors is please don't tell patients there's no hope. Pretty much everyone gave up hope on my dad. My thing is, please, as a doctor, please do everything in your power to figure out what you can do and send patients to another doctor if you can't figure out what to do. Please continue to do testing.

If we could impact somebody's life...I can't explain how horrific this was at that time, how scary to wonder if he was going to wake up. It means so much to have doctors that fight for you. You do get to a point in your life where it's so hopeless. I can't even imagine what my dad felt. 'I'm not going to last much longer'; that was his thinking. Until we found The Heartbeat Clinic it was bleak and pretty hopeless. I don't want anyone else to feel alone. identified amyloidosis as a potential cause in a patient who presented with autonomic nervous system impairment and $\mathrm{OH}$ with systemic organ involvement including gastrointestinal and kidney dysfunction. ${ }^{15}$ In two other case reports, patients with PD and cardiac conditions presented with dizziness, lightheadedness and fatigue, and were subsequently diagnosed with $\mathrm{nOH}^{16}{ }^{17}$ In one of these cases, the patient was initially suspected to have bradycardia because the symptoms overlap with those seen in $\mathrm{nOH}$ and was referred for a pacemaker before diagnostic testing for $\mathrm{nOH}$ was even considered. ${ }^{16}$ Thus, it is imperative for clinicians to screen for $\mathrm{nOH}$ when patients present with non-specific symptoms like dizziness and lightheadedness, even when there are other comorbidities present.

Autonomic function testing, including HUT, HR with deep breathing and response to the Valsalva manoeuvre, can determine whether orthostatic syncope is neurogenic in origin. ${ }^{2} 12$

Although the standard supine-to-standing BP test is more commonly used and can be performed in many clinical settings, HUT testing on a tilt table has several advantages. ${ }^{8}$ When secured to the tilt table, HUT is markedly safer for patients who experience syncope on standing. ${ }^{2}$ Passive HUT eliminates the potential confound of compensatory muscle contraction, leading to a more sensitive test. ${ }^{2}$ Abnormal response to the HR with deep breathing test or to the Valsalva manoeuvre indicates autonomic dysfunction is likely causing orthostatic symptoms. In the current case, autonomic testing led to an efficient diagnosis of $\mathrm{nOH}$, which allowed for implementation of appropriate pharmacological intervention.

When the first treatment for $\mathrm{nOH}$ does not relieve symptom burden, it is important to continue to seek a symptom-alleviating treatment. ${ }^{8}$ The goal of treatment is to restore physical capabilities and reduce potentially dangerous symptoms, not to normalise $\mathrm{BP}^{8}{ }^{8}$ The patient in this case study experienced improved quality of life once his symptoms were successfully treated with droxidopa.

Acknowledgements Medical writing assistance was provided by the CHC Group (North Wales, PA, USA). The editorial assistance was funded by Lundbeck.

Contributors SBA, WA and AS contributed to the acquisition, analysis and interpretation of data; participated in drafting the manuscript; critically revised the manuscript for intellectual content and approved the final version of the manuscript for publication. All authors agree to be accountable for the article and to ensure that

\section{Learning points}

- Orthostatic hypotension is a common cause of syncope and can be identified through orthostatic blood pressure measurements.

- A blood pressure drop of $\geq 20 \mathrm{~mm} \mathrm{Hg}$ systolic or $\geq 10 \mathrm{~mm}$ $\mathrm{Hg}$ diastolic within a few minutes of standing (or head-up tilt) accompanied by little or no increase in heart rate is suggestive of neurogenic orthostatic hypotension.

- Although patient history and physical examination findings may be helpful in the diagnostic process for neurogenic orthostatic hypotension, autonomic function testing can provide more definitive information to facilely diagnose the condition.

- If non-pharmacological measures and initial pharmacotherapy are ineffective in reducing symptoms of neurogenic orthostatic hypotension, it is critical for patient safety and quality of life that healthcare practitioners continue to seek an effective treatment to reduce symptoms, syncope events and fall risks. 
all questions regarding the accuracy or integrity of the article are investigated and resolved.

Funding The authors have not declared a specific grant for this research from any funding agency in the public, commercial or not-for-profit sectors.

Competing interests SBA received support from Lundbeck for travel and registration fees. WA has nothing to disclose. AS has received honoraria for serving on advisory boards for Lundbeck.

Patient consent for publication Obtained.

Provenance and peer review Not commissioned; externally peer reviewed.

Open access This is an open access article distributed in accordance with the Creative Commons Attribution Non Commercial (CC BY-NC 4.0) license, which permits others to distribute, remix, adapt, build upon this work non-commercially, and license their derivative works on different terms, provided the original work is properly cited and the use is non-commercial. See: http://creativecommons.org/ licenses/by-nc/4.0/

\section{REFERENCES}

1 Voermans NC, Snijders AH, Schoon Y, et al. Why old people fall (and how to stop them). Pract Neurol 2007:7:158-71.

2 Jones PK, Gibbons CH. The role of autonomic testing in syncope. Auton Neurosci 2014;184:40-5.

3 Shen WK, Sheldon RS, Benditt DG, et al. 2017 ACC/AHA/HRS Guideline for the evaluation and management of patients with syncope: $A$ report of the American College of Cardiology/American Heart Association Task Force on Clinical Practice Guidelines and the Heart Rhythm Society. J Am Coll Cardiol 2017;70:e39-e110.

4 Sheldon RS, Grubb BP, Olshansky B, et al. 2015 heart rhythm society expert consensus statement on the diagnosis and treatment of postural tachycardia syndrome, inappropriate sinus tachycardia, and vasovagal syncope. Heart Rhythm 2015;12:e41-e63.

5 Freeman R, Wieling W, Axelrod FB, et al. Consensus statement on the definition of orthostatic hypotension, neurally mediated syncope and the postural tachycardia syndrome. Clin Auton Res 2011;21:69-72.
6 Freeman R. Clinical practice. Neurogenic orthostatic hypotension. N Engl J Med 2008:358:615-24.

7 Shibao C, Lipsitz LA, Biaggioni I. ASH position paper: evaluation and treatment of orthostatic hypotension. J Clin Hypertens 2013;15:147-53.

8 Gibbons $\mathrm{CH}$, Schmidt P, Biaggioni I, et al. The recommendations of a consensus panel for the screening, diagnosis, and treatment of neurogenic orthostatic hypotension and associated supine hypertension. J Neurol 2017;264:1567-82.

9 Cheshire WP. Chemical pharmacotherapy for the treatment of orthostatic hypotension. Expert Opin Pharmacother 2019;20:187-99.

10 McDonald C, Pearce M, Kerr SR, et al. A prospective study of the association between orthostatic hypotension and falls: definition matters. Age Ageing 2017;46:439-45.

11 Ooi WL, Hossain M, Lipsitz LA. The association between orthostatic hypotension and recurrent falls in nursing home residents. Am J Med 2000;108:106-11.

12 Brignole M, Moya A, de Lange FJ, et al. 2018 ESC Guidelines for the diagnosis and management of syncope. Eur Heart J 2018;39:1883-948.

13 NORTHERA $®$ (droxidopa). Full Prescribing Information. Deerfield, IL: Lundbeck NA Ltd, 2017.

14 ProAmatine $₫$ (midodrine hydrochloride). Full Prescribing Information. Lexington, MA: Shire US Inc, 2017.

15 Pelusi S, Lombardi R, Airaghi L, et al. Progressively invalidating orthostatic hypotension: A common symptom for a challenging diagnosis. J Res Med Sci 2016;21:117.

16 Olshansky B, Feigofsky S, Cannom DS. Is it bradycardia or something else causing symptoms? HeartRhythm Case Rep 2018:4:601-3.

17 McCullough PA. Treatment of Orthostatic Hypotension Due to Autonomic Dysfunction (Neurogenic Orthostatic Hypotension) in a Patient with Cardiovascular Disease and Parkinson's Disease. Cardiol Ther 2019;8:145-50.

18 Freeman R, Abuzinadah AR, Gibbons C, et al. Orthostatic hypotension: Jacc state-ofthe-art review. J Am Coll Cardiol 2018;72:1294-309.

19 Chen-Scarabelli C, Scarabelli TM. Neurocardiogenic syncope. BMJ 2004:329:336-41.

20 Gopinathannair R, Salgado BC, Olshansky B. Pacing for vasovagal syncope. Arrhythm Electrophysiol Rev 2018;7:95-102.

21 Mathias CJ. Autonomic diseases: clinical features and laboratory evaluation. J Neurol Neurosurg Psychiatry 2003;74:31iii-41.

Copyright 2019 BMJ Publishing Group. All rights reserved. For permission to reuse any of this content visit https://www.bmj.com/company/products-services/rights-and-licensing/permissions/

BMJ Case Report Fellows may re-use this article for personal use and teaching without any further permission.

Become a Fellow of BMJ Case Reports today and you can:

- Submit as many cases as you like

- Enjoy fast sympathetic peer review and rapid publication of accepted articles

- Access all the published articles

- Re-use any of the published material for personal use and teaching without further permission

Customer Service

If you have any further queries about your subscription, please contact our customer services team on +44 (0) 2071111105 or via email at support@bmj.com.

Visit casereports.bmi.com for more articles like this and to become a Fellow 